NUREG/CR-1485, Vol. 2, No. 2 UCRL-52715-80-3

ษ

\title{
Safeguards Material Control and Accounting Program: Quarterly Report, April-June 1980
}

Andrew J. Poggio and Donald R. Dunn

Prepared for

U.S. Nuclear Regulatory Commission

\section{DO NOT MICROFILM COVER}

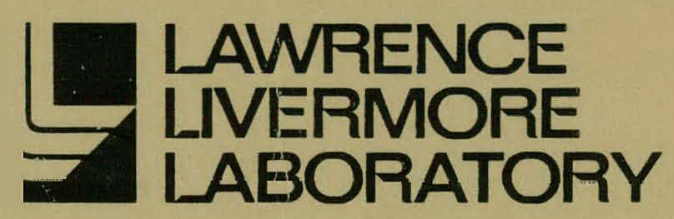




\section{DISCLAIMER}

This report was prepared as an account of work sponsored by an agency of the United States Government. Neither the United States Government nor any agency Thereof, nor any of their employees, makes any warranty, express or implied, or assumes any legal liability or responsibility for the accuracy, completeness, or usefulness of any information, apparatus, product, or process disclosed, or represents that its use would not infringe privately owned rights. Reference herein to any specific commercial product, process, or service by trade name, trademark, manufacturer, or otherwise does not necessarily constitute or imply its endorsement, recommendation, or favoring by the United States Government or any agency thereof. The views and opinions of authors expressed herein do not necessarily state or reflect those of the United States Government or any agency thereof. 


\section{DISCLAIMER}

Portions of this document may be illegible in electronic image products. Images are produced from the best available original document. 


\section{The following pages are an exact representation of what is in the original document folder.}




\section{DISCLAIMER}

This document was prepared as an account of work sponsored by an agency of the United States Government. Neither the United States Government nor any agency thereof, nor any of their employees, makes any warranty, expressed or implied, or assumes any legal liability or responsibility for the accuracy, completeness, or usefulness of any information, apparatus, product, or process disclosed, or represents that its use would not infringe privately owned rights. Reference herein to any specific commercial product, process, or service by trade name, trademark, manufacturer, or otherwise, does not necessarily constitute or imply its endorsement, recommendation, or favoring by the United States Government or any agency thereof. The views and opinions of authors expressed herein do not necessarily state or reflect those of the United States Government or any agency thereof.

This work was supported by the Unites States Nuclear Regulatory Commission under a Memorandum of Understanding with the United States Department of Energy.

\section{DO NOT MICROFILM COVER}

Available from

GPO Sales Program

Division of Technical Information and Document Control

U.S. Nuclear Regulatory Commission

Washington, D.C. 20555

and

National Technical Information Service

Springfield, Virginia $\mathbf{2 2 1 6 1}$ 
NUREG/CR--1485-Vol . 2-No:2

TI86 002779

\section{Safeguards Material Control and Accounting Program: Quarterly Report, April-June 1980}

Manuscript Completed: December 1980

Date Published:

Prepared by

Andrew J. Poggio and Donald R. Dunn

Lawrence Livermore Laboratory

7000 East Avenue

Livermore, CA 94550

Prepared for

Office of Nuclear Regulatory Research U.S. Nuclear Regulatory Commission

Washington, D.C. 20555

NRC FIN No. $\Lambda-0115$

\section{DISCLAIMER}

This report was prepared as an account of work sponsored by an agency of the United States Government. Neither the United States Government nor any agency thereof, nor any of their employees, makes any warranty, express or implied, or assumes any legal liability or responsibility for the acsuracy, completeness, or usefulness of any information, apparatus, product, or process disclosed, or represents that its use would not infringe privately owned rights. Reference herein to any specific commercial product, process, or service by trade name, trademark, manufacturer, or otherwise does not necessarily constitute or imply its endorsement, recommendation, or favoring by the United States Government or any agency thereof. The views and opinions of authors expressed herein do not necessarily state or reflect those of the United States Government or any agency thereof. 
THIS PAGE

WAS INTENTIONALLY

LEFT BLANK 
This work was supported by the U.S. Nuclear Regulatory Commission (Office of Nuclear Regulatory Research) under a Memorandum of Understanding with the United States Department of Energy. The NRC FIN number is A-0115.

The scientific editors, A.J. Poggio and D.R. Dunn, wish to acknowledge the work of those individuals responsible for each section listed below:

2.0 Application and Further Development of Automated Safeguards Assessment Tools

3.0 Development of Value-Impact Methodology

4.0 Development of Improved Guidance Capabilities for MC\&A Systems
D.W. Freeman

W.J. Orvis

A.A. Parziale

C.J. Patenaude

A.J. Poggio

P.S. Wahler

R. Al-Ayat

B. Judd*

J. Huntsman*

P. Chilton**

D.R. Dunn

G. Kufah $7 * \star$

J. McDonne $7^{* *}$

A. Vergari**

D.R. Dunn

J. McDonnel**

R. Mullen $\star \star$

* Applied Decision Analysis (ADA) Inc., Menlo Park, California

**Advanced Technology Assuciates (ATA) Inc., Dublin, California

$$
i i j / i v
$$


TABLE OF CONTENTS

FOREWORD

LIST OF ILLUSTRATIONS

ABBREVIATIONS AND SYMBOLS -

ABSTRACT

1.0 INTRODUCTION

2.0 APPLICATION AND FURTHER DEVELOPMENT OF AUTOMATED SAFEGUARDS ASSESSMENT TOOLS • • • • • • • • • • • • • • • • • • • • • 3

2.1 Introduction . . . . . . . . . . . . . . . . . . 3

2.2 Assessment of the SLIP Facility . . • . . . . . . • . . 3

2.3 Upgrade of the Structured Assessment Approach . . . . . . . 5

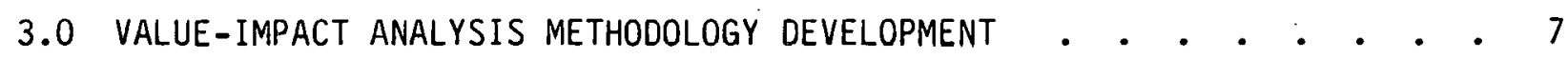

3.1 Development of Performance Measures for MC\&A Systems • • • 7

3.2 Aggregation of Performance Measures . • • • • • • • • • •

4.0 DEVELOPMENT OF IMPROVED GUIDANCE CAPABILITIES FOR MC\&A SYSTEMS • • - 12

4.1 Task Approach and Protection Principles . . . . . . . . . . 13

4.2 Graphic Terhnique and Principle Implementation . • • • • • . 15

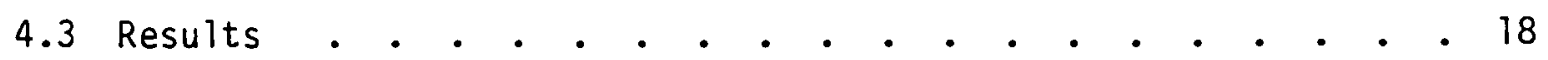

4.4 Concluding Remarks . . . . . . . . . . . . . . . . . . 19

5.0 ANALYSIS OF THE ROLE OF AN INTERFACILITY SNM ACCOUNTING SYSTEM FOR NRC SAFEGUARDS ASSURANCE • • • • • • • • • • • • • • • 20

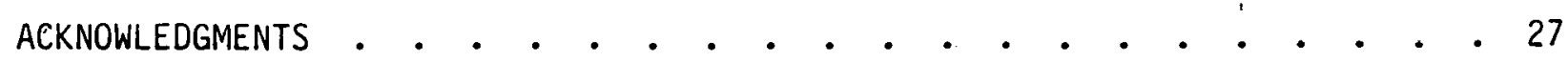

REFERENCES • • • • • • • • • • • • • • • • • • • • • • • • 28

$$
v / V i
$$




\section{LIST OF ILLUSTRATIONS}

Fig. 1. Illustration of the aggregation process . . . . . . . . 10

Fig. 2. Data.flow for aggregation and output logic . • . • . • . 11

Fig. 3. Information flow diagram, example MA system . . . . . • . 15

Fig. 4. Vulnerability event sets representation, example MA system . . 15

Fig. 5. Information flow diagram, upgraded MA system . . . . • . 16

Fig. 6. Vulnerability event sets, upgraded MA system . • • • • • 17

Fig. 7. Vulnerability event set with personnel assignment, upgraded

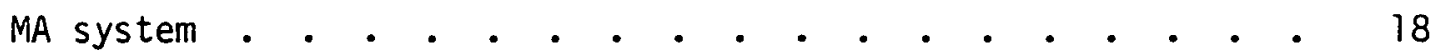

Fig. 8. Information flow diagram of the current interfacility MA system • • • • • • • • • • • • • • • • 22

$$
\text { vii/Viili }
$$




\section{ABBREVIATONS}

NRC U.S. Nuclear Regulatory Commission

MC\&A Material Control and Accounting

SAA Structured Assessment Approach

SVAP Safeguards Vulnerability Analysis Program

V-I Value-Impact

MA Material Accounting

ASM Aggregated Systems Mode 1

SEV Skip Echelon Verification

SEF Secondary Echelon Forwarding

CC Control on Controls

DC Data Control

LLNL Lawrence Livermore National Laboratory

LSD Licensee Submittal Document

SSNM Strategic Special Nuclear Materials

GMMA Generic Minimal Material Accounting

VES Vulnerability Event Sets

NMMSS Nuclear Materials Management and Safeguards System

SSRS Safeguards Status Report System 
This report summarizes the April-June 1980 activities of the Safeguards Material and Accounting Program sponsored by the U. S. Nuclear Regulatory Commission (NRC) at the Lawrence Livermore National Laboratory.

Progress is described on the application and further development of computer-based methodologies for assessing the vulnerabilities of MC\&A systems in nuclear fuel-cycle facilities. The application effort involved an assessment of a scrap processing facility with the Structured Assessment Approach (SAA) methodology. The development effort concentrated on making the SAA more user-oriented.

Work continued in providing technical analyses to assist the NRC in its development of the forthcoming MC\&A upgrade rule. The technical analyses have involved value-impact studies on the draft MC\&A upgrade rule using the LLNL Aggregrated Systems Model; specifically, progress has been made on the development of five MC\&A performance measures.

Other work has included the development of four protection principles for protecting MC\&A data from falsification. We also describe progress in analyzing the actual and potential value of an NRC interfacility material accounting system for detecting data falsification.

The above-mentioned research activities are under the auspicies of the NRC Office of Regulatory Research, Division of Safeguards Fuel Cycle and Environmental Research. 


\subsection{INTRODUCTION}

The Safeguards Material Control and Accounting Program at the Lawrence Livermore National Laboratory (LLNL) is being conducted on behalf of the $U$. S. Nuclear Regulatory Commission (NRC). The activities reported here support the Office of Regulatory Research, Division of Safeguards Fuel Cycle and Environmental Research, in two main areas. The first concerns the application and further development of computer-based methodologies for assessing the vulnerabilities of material control and accounting (MC\&A) systems for fuel-cycle facilities. The second area involves technical analyses to assist the NRC in its development of an upgrade material accounting rule for fixed-site, fuel-cycle facilities. Progress on five research tasks is discussed in this quarterly report. One task is associated with the vulnerability assessment methodology work, whereas the remaining are in support of the MC\&A upgrade rule development.

One main objective of the LLNL MC\&A program since its inception has been the development of an automated vulnerability assessment tool to assist the NRC in its licensing process with respect to both the upgraded Physical Protection regulations and the forthcoming upgraded MC\&A regulations. With in the past year, we have demonstrated and delivered to the NRC the Safeguards Vulnerability Analysis Program ${ }^{\top}$ (SVAP) and the Structured Assessment Approach $^{2}$ (SAA) for doing detailed vulnerability assessments. As discussed in a previous quarterly report, ${ }^{3}$ SVAP and SAA are complementary tools; the primary differences lie in the detail of their modeling philosophies and in the structure of their codes. We are continuing to develop these codes and to bring them to a greater state of maturity. Improvements are being made based on our experience at applying them to NRC-regulated facilities and, just as importantly, on feedback from NRC reviewers.

Section 2 of this quarterly report describes our current activity in applying both SVAP and SAA to a special nuclear material (SNM) scrap processing facility in conjunction with personnel from the NRC. Three objectives were associated with this exercise. Two were for demonstrating the tools and for NRC to benefit from the assessment results. The third was to enhance the technology transfer from LLNL to the NRC. Section 2 also 
describes upgrades now being made to the SAA with particular attention having been given to making it more user-oriented.

In Section 3, we discuss our value-impact analysis work in support of the upgrade MC\&A rule development. Our value-impact analys is is accomplished with the LLNL Aggregrated Systems Model (ASM). ${ }^{4}$ This quarterly report focuses on the ASM value-impact methodology development, specifically with respect to the development of five MC\&A performance measures. We also describe an ASM aggregration process to provide four levels. of assessment of MC\&A performance. The work reported on in Section 3 is based on data collected from interviews with Safeguards personnel at an operating facility.

Section 4 describes some of our initial work to identify protection principles for protecting material accounting systems from data falsification. The principles and concepts that have been developed will provide insight and perhaps motivation to the NRC in its development of the upgrade MC\&A rule and corresponding licensee guidance. Because of the nature and importance of this problem, systems analysts familiar with MC\&A systems as we11 as internal auditors are participating in the effort.

Section 5 describes progress in analyzing the actual and potential value of an NRC interfacility material accounting system for detecting data falsification. Work to date focuses on the relationship and capabilities of the two principal NRC SNM reporting systems. Future effort will be devoted to determining potential upgrades to the existing status quo. 


\subsection{APPLICATION AND FURTHER DEVELOPMENT OF AUTOMATED SAFEGUARDS ASSESSMENT TOOLS}

\subsection{INTRODUCTION}

The main objective of Task 1 has been to continue the application and development of the LLNL automated safeguards vulnerability assessment programs. During the April-June 1980 quarter, several upgrades for the SAA 2 have been initiated, developed, or completed, and SAA has been applied to the SLIP* facility. We have also begun to apply the SVAP ${ }^{1}$ to the SLIP facility.

\subsection{ASSESSMENT OF THE SLIP FACILITY}

On April 16, 1980, LLNL received the SLIP physical security system data from the Nuclear Regulatory Commission (NRC). These data pertained to an SNM scrap processing facility. A. Parziale of LLNL and R. Shepard and E. McAlpine of NRC had begun the data collection in February, using the SAA Licensee Submittal Document to collect the data. Upon the receipt of the data, we spent several days converting it into the format needed for an SAA assessment using an LLNL CDC-7600 computer.

The SAA program consumed two minutes of CDC-7600 Central Processing Unit time to perform the vulnerability assessment and to prepare the diverse information that forms part of its output. For example, four computer-generated outputs for the SLIP facility were provided by the SAA:

1. Monitor coverage of strategic special nuclear materials (SSNM) targets as well as entry and exit paths through the facility;

*SLIP is our name for a scrap processing facility 
2. Weak collusion analysis determined by authorized access to monitor equipment;

3. System performance based on the probabilistic performance characteristics of the monitors and their related support networks; and

4. Sensitivity to single element failure.

The original data provided by the NRC were not sufficient for a complete tampering analysis. We have generated a list of the information required and have requested the information from the NRC.

A report detailing the vulnerability assessment of this selected portion of the SLIP facility's physical security system is being prepared. It will be completed when we receive the required tamper protection information from the NRC.

As noted previously, we are also appiying SVAP to the SLIP facility to show the usefulness of the program. During FY79, LLNL completed and delivered this program to the NRC. The input data are now being collected with the aid of the SVAP Data-Gathering Handbook. ${ }^{1}$ During the July-September 1980 quarter, we will complete the assessment using SVAP and we will thoroughly document the results.

Using both LLNL detailed assessment tools to perform the physical security system vulnerability analysis of the SLIP facility serves several purposes. First, we may test both tools and their associated data-gathering and preparation aids on a real, reasonably complicated system. Second, we may observe the relative differences in the input data requirements of each tool. Third, using both programs allows us to compare the outputs of each code with regard to the system vulnerabilities. The test will help demonstrate the usefulness of both codes, and will indicate their resource requirements in manpower and computer time. 


\subsection{UPGRADE OF THE STRUCTURED ASSESSMENT APPROACH}

Considerable effort has also been devoted to improving or upgrading the SAA. The main goals have been to improve its overall efficiency, to improve its ability to deal with complex, connected systems, and to make the SAA user-interface less complicated.

To make the SAA more user-oriented, we have devoted significant resources to upgrading the SAA input package, i.e., the package that prepares the data in a format suitable for processing by SAA. The SAA input package consists of three programs: a facility description program, a material accounting system description program, and a preprocessor program. Each program is to be written and run on a Tektronix 4054. Also part of the input package, but not computer-based, is an SAA data-gathering handbook meant to aid the analyst in data collection. This handbook will be described later.

The SAA facility description program has been completed and tested. This user-oriented, minicomputer-based program is used for converting facility safeguards data into SAA-acceptable form. It has been designed as an interactive program to speed entering the data and to allow consistent and orderly input with numerous checks and correction capabilities. Once the data have been entered, the program writes a data tape containing all the facility data that are entered into the CDC 7600 computer at LLNL.

We are preparing a user's manual for the facility description program. The user's manual will accompany the facility description program, explaining its operating characteristics and detailing the mechanics and logic of entering data. The user's manual will replace the parts of SAA Vol. $2^{2}$ that pertain to user's entry of facility data.

Another effort under way is the development of a minicomputer-based SAA preprocessor. The preprocessor will probably not be completed during this fiscal year. The object of the preprocessor is to perform extensive errorand consistency-checking, to validate the input data, and to point out any possible problems. Since the preprocessor will also be operational on the minicomputer, the data can be entered and checked at a minicomputer data-input statiun ralher than in the mainframe computer. This will facilitate corrections and updates. 
Operating the SAA preprocessor is straightforward. The preprocessor will produce several edits, i.e., printouts of safeguards system elements that have some special relationship to another safeguards element. For example, the area edits will produce a printout for each area in a facility that will contain a list of all the adjacent areas and barriers plus all the personnel, monitors, wires, and process elements that are either in the area or are allowed in the area. Once the edits are complete, the preprocessing code will check the wiring and process elements to ensure continuity of the connections as they pass from area to area. Similar. checks and comparisons will be performed on other safeguards elements.

As an additional aid for data-gathering, we have been developing an SAA data-gathering handbook. The handbook is written in a form suitable for use in the field. The bulk of the physical security portion of this handbook was completed during this quarter. During the fourth quarter of FY80, we intend to further improve its content and edit the physical security portion of the handbook prior to pubiication. The material control and accounting (MC\&A) portion of the data-gathering handbook is also being developed but at a slower rate. We discussed several options for these forms and we are soliciting comments from staff members regarding an appropriate format. 


\subsection{VALUE-IMPACT ANALYSIS METHODOLOGY DEVELOPMENT}

Contributors: Rokaya Al-Ayat, Bruce Judd,* and Jean Huntsman*

We are preparing a Value-Impact (V-I) Analysis of the MC\&A Upgrade Rule using the LLNL Aggregrated Systems Model (ASM). ${ }^{4}$ Data collection for the Aggregated Systems Model started late last quarter and continued this quarter. The input data for the ASM were collected from Safeguards personnel at an operating facility; subsequent analysis of these data form the basis for the construction of a base case data set (reference data) for V-I analysis of the MC\&A upgrade rule.

The following sections present a brief description of the performance measures in our $V-I$ analysis and an overview of the process used to convert the ASM input data (MC\&A information collected at the facility) to the required output (system's performance measures). Section 3.1 discusses the logic used to arrive at performance measures and includes definitions of some of these measures. Section 3.2 explains the aggregation process that turns input data into output measures. This section also explains the intermediate data required to perform the aggregation process.

\section{1 DEVELOPMENT OF PERFORMANCE MEASURES FOR MC\&A SYSTEMS}

The performance of an MC\&A system is determined by the characteristics of the system's two principal functions: the alarm function ano the corresponding alarm resolution function. The MC\&A alarms represented in the base case facility model are identified as late alarms because they do not occur in time to stop a diversion attempt.

Overall MC\&A system performance should be analyzed in terms of measures that:

ॠApplied Decision Analysis (ADA), Inc., Menlo Park, California 
- accurately describe system performance;

- provide a consistent base for comparisons among facilities; and

- have reasonable data input requirements (in the sense of amount and availability of required data).

The ASM analyzes system performance in these terms by producing a set of quantitative measures that reflect system performance in each of the following statistical families: (1) alarm probabilities, (2) times to alarm, (3) resolution probabilities, (4) times required for resolution, and (5) diversion and deterrence indexes.

These measures are computed in a V-I analysis for the overall MC\&A system and for lower levels of aggregation. Each of the first four output categories includes a variety of similar measures from different aggregation levels. For instance, performance can be conditioned on an initiating event (diversion, falsification only), quantity of SNM, and location in the facility. The next section describes the levels of aggregation considered in the ASM.

\subsection{AGGREGATION OF PERFORMANCE MEASURES}

The four main levels of aggregation used in the ASM are listed below in order of increasing aggregation:

LEVEL 1: Assessed input data

LEVEL 2: Performance by individual scenario

LEVEL 3: Performance by initiating event types (further breakdown by quantity and/or location also possible)

LEVEL 4: Performance aggregated over all initiating events (further breakdown by quantity and/or location also possible).

The assessed input data must be compatible with the more aggregated measures. This means that the input data requirements include alarm probabilities, expected times to alarm, resolution probabilities, and expected times to resolution. A11 the input data must be assessed for each individual alarm event and resolution event of each scenario. These input data reflect 
an even lower level of aggregation (say, LEVEL 0) that was not listed above, because they represent an implicit aggregation step taken during the facility assessment.

An evaluation procedure such as the ASM requires compatible input measures for all alarms and resolution procedures, yet the various alarms and resolution procedures may have a wide range of characteristics. For example:

- Alarm mechanisms can range from complex measurement devices to simple observations (e.g., missing item) to purely external alarms (e.g., communicated threats).

- Some alarms entail reliability and detection sensitivity issues, while others may not.

- Different alarms and resolution procedures vary widely in their dependence on the quantity of SNM involved.

These different features are combined implicitly during the facility assessment to arrive at input measures that are common to all alarms and resolution procedures. These input measures, listed under LEVEL 1, provide the standardized base from which analys is begins.

Figure 1 depicts the basic aggregation structure of the ASM for the sample case of Expected Time to Alarm [E(Time to alarm)]. It shows how outputs from one level of aggregation combine to produce the outputs of the next level.

Figure 2 summarizes the data required to move from each level of aggregation to the next more aggregated level. Figure 2 shows that in order to move from performance conditioned on scenarios (LEVEL 2) to performance conditioned on initiating event (LEVEL 3), orily relative adversary frequencies, relative falsification frequencies, and relative error condition frequencies are required. Similarly, movement from the LEVEL 3 measures to the overall performance measures (LEVEL 4), requires frequencies of diversions, falsifications, and error conditions relative to each other. With the additional input of absolute frequencies of the three initiating event types, the diversion index and deterrence index arc calculated. 


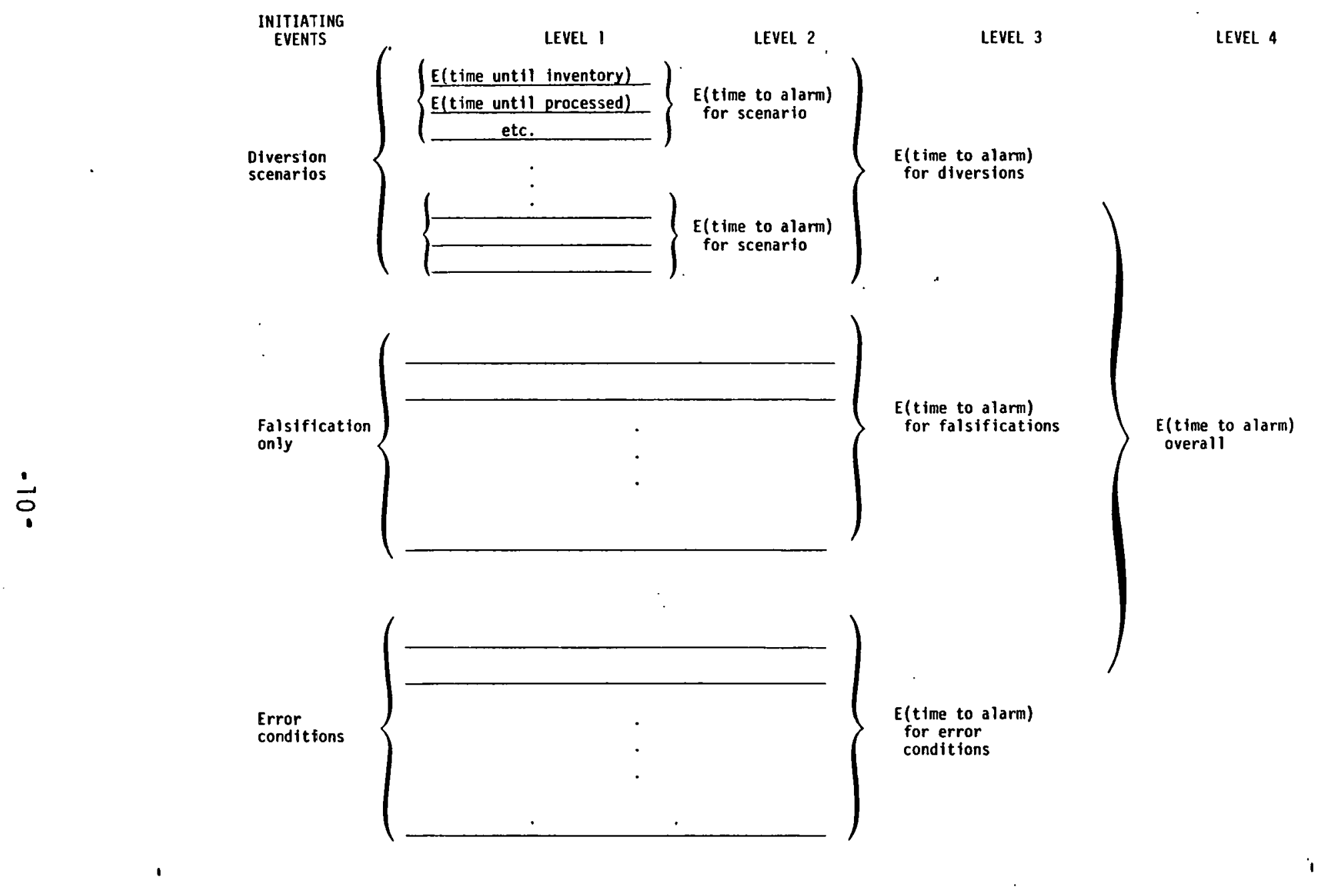

Figure 1. Illustration of the Aggregation Process 


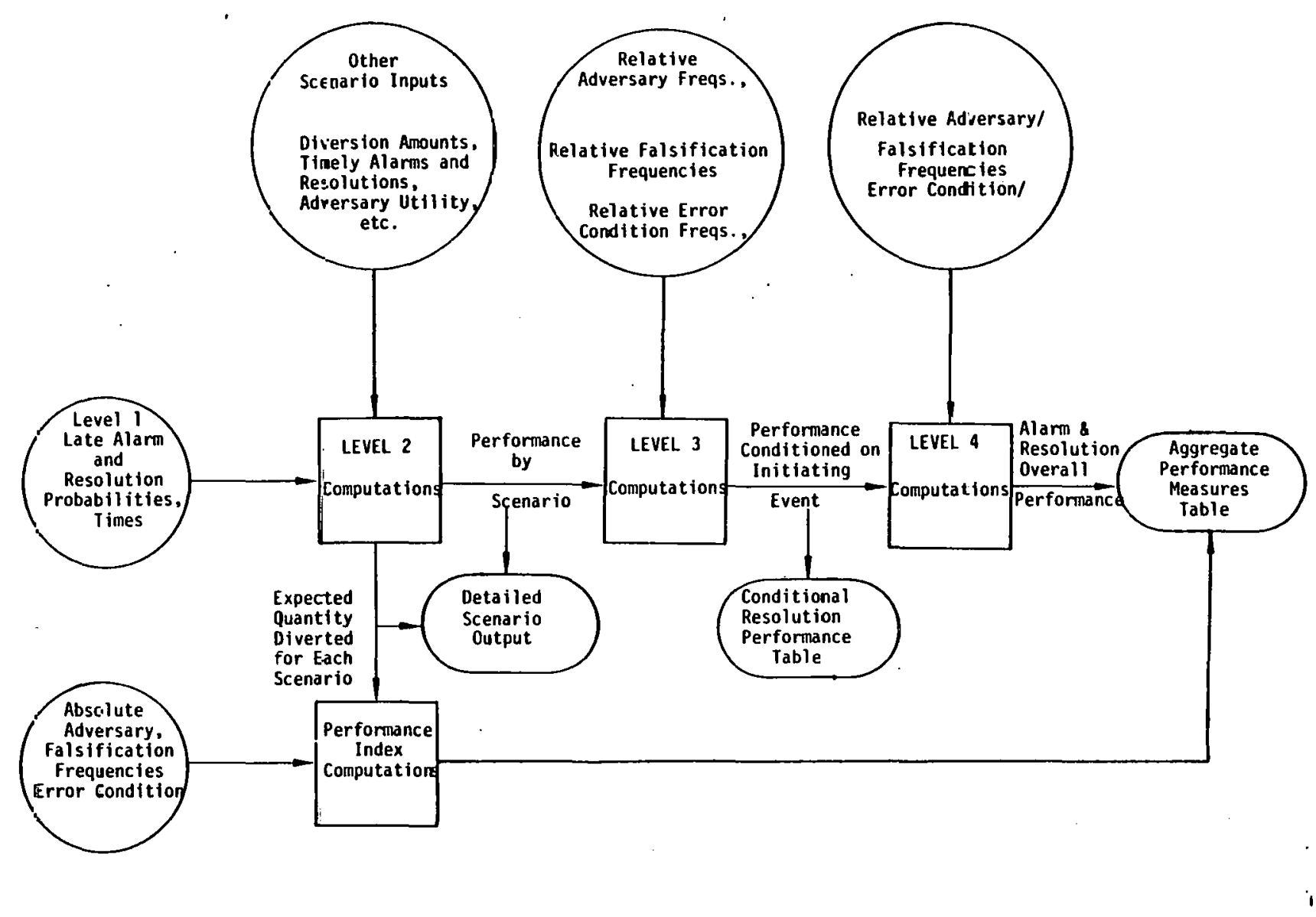

Figure 2. Data Flow for Aggregation and Output Logic 


\subsection{DEVELOPMENT OF IMPROVED GUIDANCE CAPABILITIES \\ FOR MATERIAL CONTROL \& ACCOUNTING SYSTEMS}

Contributors: P. D. Chilton, * D. R. Dunn, G. E. Kufahl,*

J. L. McDonnel, * and A. A. Vergarj*

The April 1978 MC\&A Task Force Report ${ }^{1}$ identified weaknesses in current material accounting (MA) systems. As a result of the Task Force Report, LLNL undertook two studies to support an upgrade rule for MA. The first study, completed in FY79, involved the systematic evaluation and critique of current MA regulations. The 1979 study led to the development of a generic, minimal MA (GMMA) system and a vulnerability assessment of its associated information flow diagrams. 2

The current study is a follow-on effort that further examines the generic system vulnerabilities and develops or recommends three safeguards guidance capabilities for MC\&A systems:

1. concepts, principles, and methods for protecting MA data from falsification;

2. MA checks and balances for detecting theft or diversion; and

3. MA organizational criteria that support safeguards effectiveness.

Four protection principles have been developed that will provide protection when implemented in accordance with specified organizational criteria. These principles are presented in Section 4.1. We have chosen as a safeguards effectiveness measure the number of colluders required to tamper with and defeat the MA system. For the examples provided, the degree of safeguards effectiveness was considered adequate if three colluders were required to successfully defeat the MA system.

*Aavanced Technology Associates (ATA), Inc., Dublin, California. 
This follow-on study is based on the GMMA system and its associated information flow diagrams, ${ }^{2}$ developed in FY79. The GMMA system is minimal because it uses only the minimal safeguards and accounting elements needed to meet federal requirements. Our analysis identified all possible vulnerability events and possible protection paths for theft or diversion scenarios.

A vulnerability event defines a minimal combination of safeguards accounting elements (e.g., reports, records, documents, measurements, controls, and consistency checks) that, if accessed or tampered with, could defeat the loss detection mechanisms of the GMMA system. A vulnerability event set (VES) contains all vulnerability events for a particular loss detection mechanism. The three loss detection mechanisms of the GMMA system are (1) the Inventory Procedure, (2) the Item Verification Procedure, and (3) the Item Quantity Procedure.

In this study, we use a graphic technique that aids in understanding a VES. This technique can be used to analyze directly the Boolean equations determined from the information flows within the MA system. It was used here to select protection paths and to analyze the effect of protection principle implementation.

A protection path for a given VES contains at least one MA element from each vulnerability event of the set and defines the accounting elements that must be protected or controlled to achieve the degree of assurance desired. A transformation can be made from MA elements to the personnel assignments of the functions represented by the MA elements. A degree of assurance or protection can then be described in terms of collusion of participants; for this study, protection against any two colluders was specified and achieved for the GMMA system for purposes of illustration.

\section{1 TASK APPROACH AND PROTECTION PRINCIPLES}

To provide the degree of assurance desired, all three loss detection mechanisms of the complete MA system must be protected. The VES containing all the vulnerability events of the three loss detection mechanisms must be addressed. 
Protection paths will contain at least one element of each of the defined vuinerability events. Although thousands of protection paths are possible, many elements that require protection are common to all paths. The procedure followed in applying protection principles was to select protection paths containing a minimal number of elements (about 30 ) and several possible alternate minimal protection paths.

Each individual element of these protection paths was analyzed by auditors with considerable experience. After each element was investigated separately, the elements were assigned to four groups: the elements of each group required similar protection procedures. From this grouping we derived the four protection principles. The mathematical basis for each of the principles is presented later. The four protection principles are as follows:

1. The Data Control Rule (DC). This principle assures that sufficient controls be involved in the handling of data such as the introauction of original data into a system.

2. The Control on Controls Procedure (CC). This principle assures that control procedures that function to ensure integrity and accuracy of measurements and original data are themselves protected.

3. The Skip Echelon Verification (SEV). This verification process requires assurances that data provided to MA elements, such as consistency checks, are properly used and that correct data are reported to the next echelon. Verification is accomplished by personnel sending (transmitting) the data.

4. The Secondary Echelon Forwarding (SEF). This verification process requires that recipients of data verify that the data were used properly by the sender. As with SEV, an alternative report results, and it can be used to verify formal reports and which then be destroyed.

After these principles are implemented, the analysis proceaure followed was to make the transformation from MA elements to personnel assignments. Organizational criteria were then specified for the GMMA system to assure the level of protection desired. 


\subsection{THE GRAPHIC TECHNIQUE AND PRINCIPLE IMPLEMENTATION}

We have applied our graphic technique for representing VES to the following information flow diagrams for illustration. The letters represent MA elements, arrows indicate direction of information flow, and crossed arrows indicate controls.

Figure 3 shows the information flow for our first example of an MA system. As shown in this figure, $D$ controls $C$ in the sense that $C$ cannot occur unlesS $D$ does. Figure 4 is the graphic VES representation for this same example. The vulnerability events of the example are elements $A, B$, and $E$ alone and the combination of $C$ and $D$. This figure should be interpreted in the following manner: shows tampering with any path (i.e., MA elements) from point 1 to point 2 can potentially defeat the MA system.

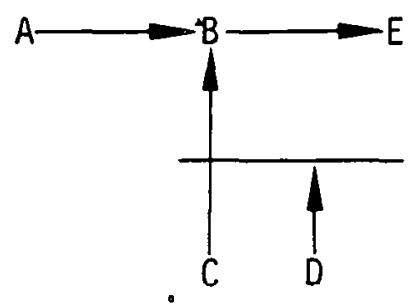

Fig. 3. Information flow diagram, example MA system.

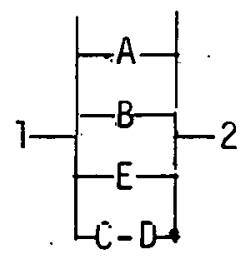

Fig. 4. Vulnerab1lity event sets represellalion, example MA system. 
Protection paths for the VES are $A$ and $B$ and $E$, and either $C$ or $D$ (or parts of $C$ and $D)$. Nominaliy, protection paths contain one element from each event.

To illustrate the protection principles, refer to Figure 3 , the information flow diagram for the example MA system, and to Figure 5, an upgraded MA system that has had control elements added. To illustrate the DC rule, a control element $F$ is introduced to protect $A$ as shown. To illustrate the CC principle, a control element $G$ is introduced to control element $D$, as shown. To illustrate SEV, control elements $H$ and $I$ are introduced to control information flowing to $E$ from $B$. The same information that passes to $B$ is also transmitted to $H$ and $I$ as shown. To illustrate SEF, the NRC (presumed invulnerable) is added to the model, as are the control elements $J$ and $K$, which control data passing from $E$ to the NRC. The data received by $J$ and $K$ are the same as those received by $E$.

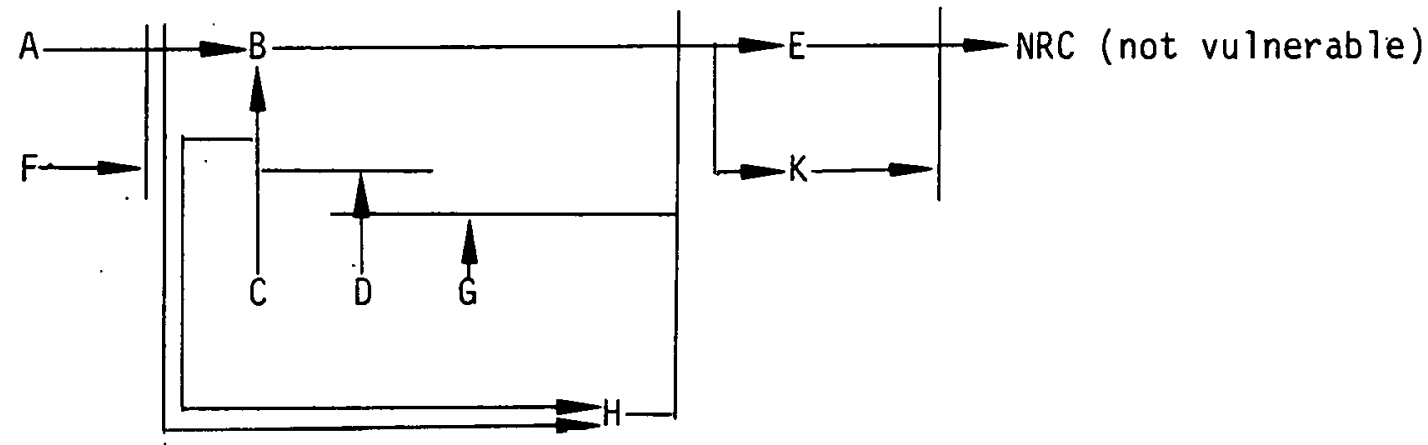

Fig. 5 Information flow diagram, upgraded MA system.

The VES for the upgraded system with the four protection principles implemented is shown in Fig. 6. For the DC rule, the vulnerability event sets which contained $A$ alone will now contain $F$ also. For the CC rule, the vulnerability events that contained just $C$ and $D$ will now contain $G$ also. For 
SEV, the path that contained B alone now becomes two paths. For SEF, the path that contained $E$ alone also becomes two paths with a vuinerability event set for each path.

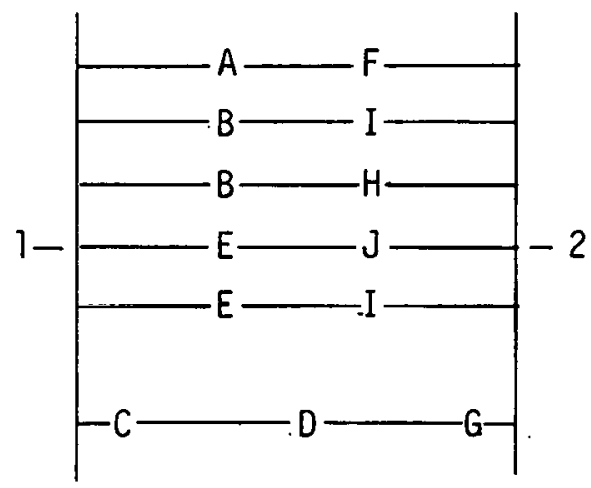

Fig. 6. Vuinerability event sets, upgraded MA system.

An organizational structure results after the MA functional elements are transformed to personnel assignments. The choice of transformation must make defeating the MA system impossible for two colluders for our example problem. In the upgraded $M A$ system, MA functions $A, B, C, D$, and $E$ represent the original system and are assigned to individuals $a, b, c, d$, and $e$, respectively. The control function $F$ is performed by two identified persons, $f_{1}$ and $f_{2}$, to meet the organizational criteria. Control function $G$ is also assigned to individual $\mathrm{g}$. The control function $H$ is assigned to personnel $c$ and $d$ because they are senders of data to element $B$. Control I is assigned to personnel $a$ and $f$ because they also send independent data to element $B$. The control functions $J$ and $K$ are assigned to individuals at the NRC who are assumed invulnerable. The resulting VES with personnel assigned is as shown in Fig. 7. Note that because personnel assigned to control functions $J$ and $K$ are representing the NRC, $e$ is not a vulnerability and consequently does not appear as a vulnerability event set. 


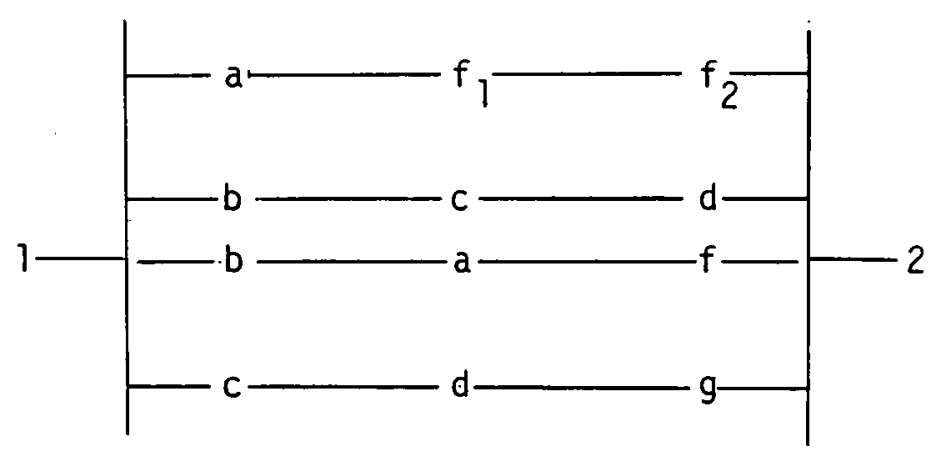

Fig. 7. Vulnerability event set with personnel assignment, upgraded MA system.

A number of assertions have been made in this section without explaining the rigorous underlying basis in Boolean algebra applied to network theory with "and" and "or" gates, etc. The algebra can be easily done, and the graphic technique described here provides a concise and intuitive shorthand.

\subsection{RESULTS FOR THE GMMA SYSTEM}

There were 165 possible one- or two-element vulnerability events in the GMMA system. Applications of the four protection principles to elements of selected protection paths (about 30 elements) for the complete GMMA system resulted in a VES, transformed to personnel assignments, in which all vulnerability events were represented by at least three identified people with the exception of two. However, applying these principles further afforded the desired protection.

We believe that applying these principles to a specific license situation would yield similar results. The effort required to implement the licensee environment, however, needs to be determined.

Considered in this study were accounting elements and corresponding persons who perform the functions of those accounting elements. MA data falsification by other than individuals with authorized access might be possible if access to the MA system were available to others (e.g., janitorial force). In an actual licensee environment, this situation would have to be investigated. 


\subsection{CONCLUDING REMARKS}

Documentation of this work has begun. The final documentation will motivate the protection principles in greater detail and will also better address organizational considerations. 


\subsection{ANALYSIS OF THE ROLE OF AN INTERFACILITY SPECIAL NUCLEAR MATERIAL ACCOUNTING SYSTEM FOR NUCLEAR REGULATORY COMMISSION SAFEGUARDS ASSURANCE}

Contributors: D. R. Dunn, J. L. McDonnel,* and R. K. Mullin*

The primary purpose of this task is to analyze the actual and potential. value and impact of an interfacility NRC material accounting system involving information flows between licensed facilities, NRC headquarters, NRC regional offices and the DOE/NRC Nuclear Materials Management Safeguards System (NMMSS) facility at Oak Ridge, Tennessee.

The primary objectives of this task in view of the above purpose are threefold:

1. To characterize current national MC\&A information flows and corresponding detection mechanisms;

2. To identify accounting checks and audits that could be employed using currently available data; and

3. To determine additional data needs and corresponding safeguards checks and auditing mechanisms.

This quarterly report principally addresses the first of these objectives.

During the previous quarter we focused on collecting and reviewing narrative descriptions of the NMMSS and the NRC Safeguards Status Report System (SSRS). Whereas NMMSS is a shared DOE/NRC material accounting data base system, SSRS is an exclusive NRC regional office data base system. The SSRS is the primary mechanism by which the NRC regional offices report material accounting status data on licensed facilities to the NRC headquarters Office of Inspection and Enforcement. To clarify our understanding of both the NMMSS and SSRS, we conducted extensive interviews with NRC headquarters and Region 5 personnel. We also extensively interviewed the NMMSS operators

ॠAdvanced Technology Associates (ATA), Inc., Dublin, CA 
at Oak Ridge, Tennessee, and the Boeing Computer Services personnel familiar with the NMMSS.

In this section, we first focus on the NMMSS and comment on its organization and effectiveness, then focus on the SSRS and comment on its use. We also show our observations and comments on the national data flow process in an information flow diagram (Fig. 8).

The block diagram in Fig. 8 depicts our understanding of current national material accounting data flows. The numbers associated with the boxes refer to the corresponding notes in Table 1, which summarize major points for each box. As can be seen from the figure, information flows from the licensees to the NRC via the two independent reporting systems, SSRS and NMMSS.

The NMMSS data are principally book-inventory and individual transaction information (Fig. 8, boxes 1-4), which is reconstructed and made available to the NRC through the Safeguards Monitor Report and through other reports as requested (Fig. 8, boxes 21 and 22 ). Some limited detection use is made of the data and will be reported on in a future quarterly.

The regions play an important role in detecting internal falsification and possible material diversions. The Regions' inspection takes place at the licensee facility with all the records of the licensee available to the inspectors. Circumstances that could indicate a deception are resolved at the level of the Regions before formally reporting it to Headquarters. These circumstances are things other than abnormal operating losses (Fig. 8, data.of box 5), such as a beginning inventory that differs from the ending inventory. Our perception is that such checks and balances are informal and ad hoc. Formal reporting by the Regions to Headquarters is accomplished using the SNM Inventory Balance Report (NRC Form 327, Fig. 8, box 11) for each facility. The compilation of the 327 forms is called the White Book.

Data received by the Regions from the NMMSS (Fig 8, boxes 2 and 22) are used principally to assist in their audit procedures and not to resolve conflicts. 


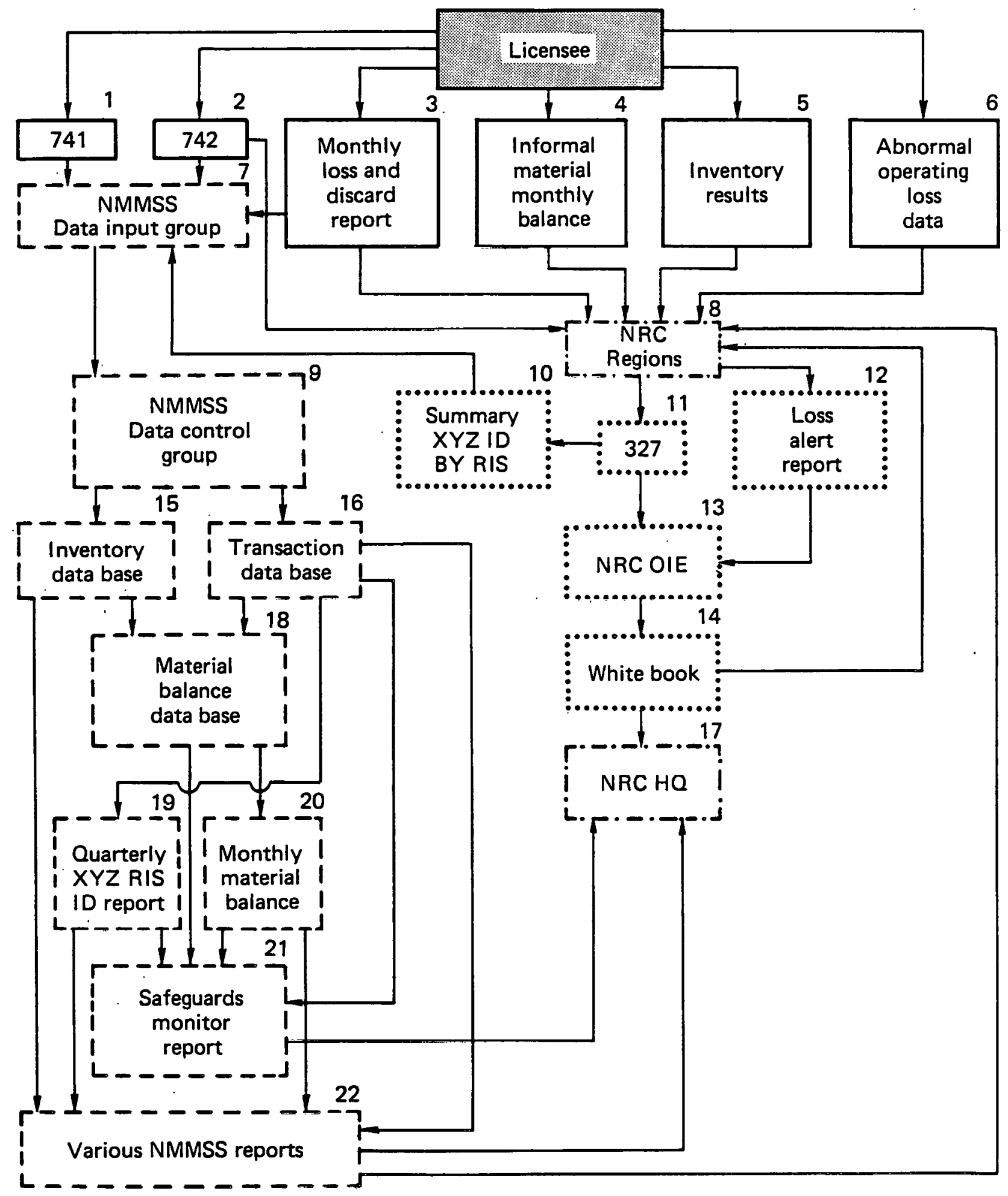

Fig. 8. Information flow diagram of the current interfacility MA system. 
Table 1. Information flow diagram notes

1. 741 is Transaction Report. Contains Shipper Receiver Difference Data Sent day of transaction to receiver and NMMSS Sent within ten days of receipt to sender and NMMSS Contains Identification, weight \% of Isotope, Isotope weight Limits of error of element and isotope, Nature of transaction

2. 742 is Mar. 31 and Sept. 30 Book Inventory (Last PI \& transactions) By elements \& Isotopes, Beginning inventory, Receipts, Removals, Degradation to other materials (i.e., result of blending) Decay, fission and transmutation, Normal operational losses/ Measured discards, accidental losses, approved writeoffs, Inventory differences, Ending inventory.

Composition status of ending inventory (process, scrap, etc, by weight \& isotope).

742 Courtesy copy sent to regions but not used by them.

742 only prepared twice. a year by regulations.

3. Monthly loss and discard Report. Informal report by letter, etc. used by regions for inspections. Unknown use by $\mathrm{NRC/HQ}$, required by 1 ic. cond.

4. Informal Material Monthly Balance. Phone call to regions, informal use Licensee conditions, can be reconciled with P.I.--Monthly Book

5. Non Normal Operating Losses Data. When observed, fastest means.

6. Inventory Results-Result of physical inventory by RIS. May use any date as anniversary. Primary input to Form 327 
Table 1. Cont'd.

7. Data Input Group at ORNL. Resolve errors informally with Licensee. New 741 or 742 submittal.

8. Regions-Audit facilities three times per year (Inspections) Resolve inventory data errors with licensee informally before preparing final 327. Region sends 327 at every inspection and every P.I.

9. K25. These people are NMMSS. They also resolve some errors informally with licensee. New 741 or 742 prepared but old one saved.

10. Summary XYZ ID data by RIS. Taken from 327.

11. 327 SNM Inventory Balance Report. By RIS QTY at start, Receipts, shipments, measured discards, QTY at end, ID, Bias adjusted ID (measurement bias), calculated LEID, cumulative ID, ID as \% of additions to process to removals from process, LEID as \% of additions to process to removals from process.

Cum. ID last 12 mos., (ID prior period, ID current period, used to explain differences. Not used in White Book)

12. Loss alert reports. NRC messages to $H Q$ responding to abnormal operating losses.

13. NRC-OIE--HQ for Regions

14. Safeguards Status Report (System) (SSRS). The White Book. Classified report, compilation of 327 forms, limited distribution, 4-6 mos. old from 327

15. Inventory Data Base. 742 Data

16. Transactions Data Base. 741 Data 
Table 1. Cont'd.

17. HQ/NRC. All those recipients of SSR White Book.

18. Material Balance Data Base. Derivation

19. Quarterly XYZ RIS ID Report

20. Monthly Material Balance. Done on 10th for previous month. Depends on receipt of 741 - Flagged errors assigned a processing data for subsequent month. Data corrected and entered into $15 \& 16$ when correction occurred. Date of original notation is preserved and noted.

21. Safeguards Monitor Report. Customer requests with in capability of NMMSS.

22. Various NMMSS Reports (about 150 different reports). 
Some analysts have concluded that the NMMSS system is an invalid source of inventory information because of differences between the NMMSS and SSRS in reporting times and in the data reported, and because the NMMSS does not receive physical inventory data through SSRS. Although this may be a correct conclusion for other reasons, it is not because SSRS data are not received. We observe that twice each year when the Book Inventory is prepared, the NMMSS system could independently produce data identical to that found in the White Book. Considering how old the White Book data are when published, NMMSS may actually be a better source of inventory data.

Examining the contents of blocks 1 through 6 of the information flow chart of Fig. 8 will show that much data are currently transmitted from licensees to the NRC. If these data were reported formally and promptly, then some of the issues above could be resolved. Unless some new data are identified that are not compatible with either reporting system, a new system is unlikely to produce more than the present systems would with only minor changes.

The remaining effort in Task 5 will involve identification of specific currently reported data that might now be used to detect internal falsification. We will then try to suggest other data that might be reported which could be useful for the same purpose. 
The authors wish to acknowledge R. Shepard for continued support. The authors also wish to thank A. D. Scarpetti, J. D. Attebery, and R. Mayo for editorial assistance and M. M. Kirschten and D. M. Zerr for preparing the manuscript. 


\section{REFERENCES}

1. P. S. Wahler, Safeguard Vulnerability Analysis Program (SVAP) Data-Gathering Handbook, Lawrence Livermore National Laboratory, Livermore, Ca., NUREG/CR-1169, Vols. I and II; UCRL-52731, Vols. 1 and 2, (1980).

2. A. A. Parziale and I. J. Sacks, Structured Assessment Approach Version 1. The License Submittal Document Content and Format for Material Control and Accounting Assessment, Vol. 2, Lawrence Livermore National-Laboratory, Livermore, Ca., UCRL-52735, Vo1. 2; NUREG/CR-1233, Vol: II, (1980).

3. United States Nuclear Regulatory Commission, Report of the Material Control and Material Accounting Task Force, NUREG-0450 (1978).

4. J. Lim and J. Huebel, Material Accounting As Required by U.S. Nuclear Regulatory Commission: Capabilities and Vulnerabilities, Lawrence Livermore National Laboratory, Livermore, CA., UCRL-527.34; NUREG/CR-1192 (1980). 
Technical Information Department $\cdot$ Lawrence Livermore Laboratory University of California - Livermore, California 94550

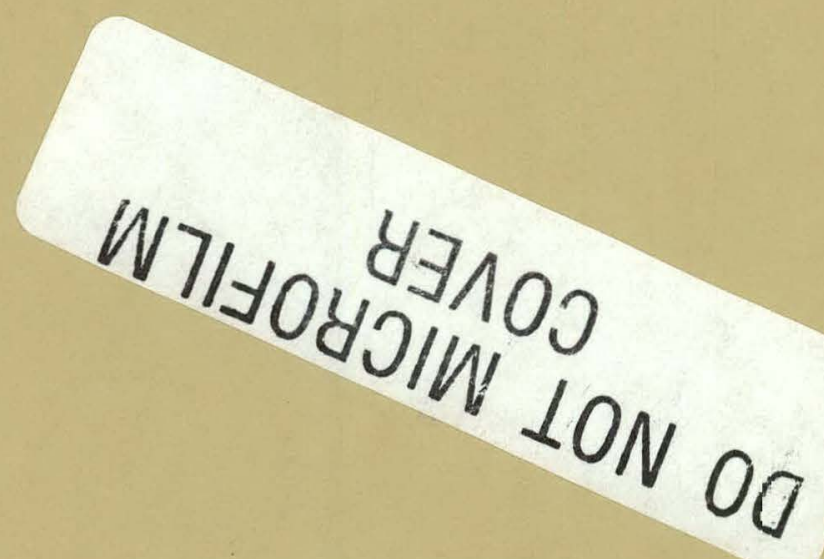

